\title{
Da invisibilidade à ação no campo político: dinâmicas da juventude rural nos processos participativos das Conferências Nacionais
}

\author{
Joana Tereza Vaz de Moura'
}

Marcos Aurélio Freire da Silva Júnior ${ }^{2}$

Jenair Alves da Silva ${ }^{3}$

\section{Resumo}

A juventude rural teve uma participação ativa nas Conferências Nacionais de Juventude, entre 2008 e 2015, conseguindo pautar várias demandas que foram acolhidas nas deliberações finais. Como foi possível que um grupo tradicionalmente invisível na sociedade conseguisse ter voz? Este artigo tem como objetivo principal analisar o papel da juventude rural no campo político (BOURDIEU, 1989; 2011) e as estratégias e narrativas utilizadas. Mostramos que o fato da temática da juventude ganhar força no interior das organizações rurais e receber maior atenção do Governo Federal nos anos 2000, possibilitou que os jovens, enquanto agentes sociais, se destacassem nesse processo.

\section{Palavras-chave}

Juventude rural; Conferências nacionais; Desenvolvimento agrário; Campo político; Narrativas.

From invisibility to the action in the political field: dynamics of rural youth in the participatory processes of National Conferences

\begin{abstract}
Rural youth had an active participation in the National Youth Conferences, between 2008 and 2015, managing to settle several demands that were accepted in the $\mathrm{fi}-$ nal deliberations. How was it possible that a group traditionally invisible in society could have a voice? This article aims to analyze the role of rural youth in the political field (BOURDIEU, 1989; 2011) and the strategies and narratives used. We show that the fact that the theme of youth gained strength within rural organizations and received greater attention from the Federal Government in the 2000 s, made it possible for young people, as social agents, to stand out in this process.
\end{abstract}

Keywords

Rural youth; National conferences; Agrarian development; Political field; Narratives.

Artigo recebido: fevereiro de 2021

Artigo aprovado: abril de 2021 


\section{Introdução}

Os estudos sobre a juventude ainda hoje marginalizam o entendimento da categoria juventude rural. Segundo Farrugia (2014), os jovens rurais permanecem marginais ao desenvolvimento teórico em estudos sobre a juventude. Para o autor, essa invisibilidade tem a ver com o processo histórico de construção do pensamento sociológico baseado na concepção de modernidade, separando e dicotomizando o urbano e o rural. "Perspectivas dominantes em ambas as teorias sociológicas clássicas e contemporâneas construíram uma dicotomia teórica entre o rural e o urbano" (FARRUCIA, 2014, p. 295). Desse ponto de vista, a gestão das sociedades modernas seriam sociedades urbanizadas, simplificando todo o processo de constituição da urbanização nos diferentes países e deixando de compreender os fenômenos presentes em pequenos e médios municípios e a relação com o espaço rural. Nessa compreensão, o rural desapareceria e, portanto, não precisaria ser problematizado. No Brasil, esta discussão ganhou relevância nas abordagens desenvolvidas por alguns autores como Milton Santos e Octavio lanni que trabalharam “a ideia de "urbanização do rural”, segundo a qual, o rural tenderia a desaparecer, tornando-se urbano" (JACINTO, MENDES, PEREHOUSKEI, 2012, p. 175). Esse pensamento refletiu nas discussões sobre a juventude rural que, até pouco tempo atrás, era uma categoria invisível não muito discutida acadêmica e politicamente, uma vez que a expressão de mobilização no campo se dava em torno dos sindicatos rurais e das pastorais da Igreja Católica, em que predominava nesses espaços os homens adultos.

Assim, como foi possível que uma categoria invisível durante anos conseguisse pautar demandas específicas nas $1^{a}, 2^{a}$ e $3^{a}$ Conferências Nacionais de Políticas Públicas de Juventude no Brasil? Ainda mais quando havia interesses representados pelas juventudes dos mais diversos segmentos, tornando as políticas públicas de juventude um campo de disputas? 
Diante disso, este artigo tem como objetivo principal analisar o papel da juventude rural no campo político (BOURDIEU, 1989; 2011) e as estratégias e narrativas utilizadas para pautar suas demandas nas Conferências Nacionais de Políticas Públicas de Juventude. Compreendemos, assim como Bourdieu (2011, p. 194), que utilizar a ideia de campo político nos permite compreender e construir a "realidade que é a política ou o jogo político". O campo político é definido como

um microcosmo, isto é, um pequeno mundo social relativamente autônomo no interior do grande mundo social. Nele se encontrará um grande número de propriedades, relações, ações e processos que se encontram no mundo global, mas esses processos, esses fenômenos, se revestem aí de uma forma particular (BOURDIEU, 2011, p.195).

Portanto, buscamos entender como os jovens rurais vão se constituindo enquanto agentes na dinâmica desse campo político da juventude no Brasil, inclusive produzindo e operando uma "competência específıca" para jogar o jogo próprio desse campo, adquirindo capitais para transformar as relações de força e construindo narrativas para sensibilizar outros grupos (BOURDIEU, 2011, p. 199; POLLETTA, 2006).

Para dar conta de responder os objetivos do trabalho foram necessárias três etapas de pesquisa. Na primeira etapa, levantamos informações nos sites das principais entidades representativas do meio rural (Federação dos Trabalhadores da Agricultura Familiar-Fetraf, Confederação Nacional dos Trabalhadores Rurais Agricultores e Agricultoras Familiares- Contag, Movimento dos Trabalhadores Rurais Sem Terra MST, Pastoral da Juventude Rural - PJR) sobre as narrativas produzidas nesses espaços sobre a temática da juventude rural.

A segunda etapa foi destinada a fazer um levantamento de documentos das Conferências Nacionais de Juventude (2008, 2011 e 2015) e do I Seminário Nacional de Juventude Rural e Políticas Públicas (SNPPJR), realizado em 2012, promovido pela Secretaria Nacional de Juventude (SNJ) em parceria com o Ministério do De- 
senvolvimento Agrário (MDA) ${ }^{4}$. A partir desse evento foi produzido o documentário "Pé no Formigueiro", de onde retiramos falas dos participantes para compor as narrativas. Foi importante, também, resgatar as ações e deliberações do Comitê de Juventude do Conselho Nacional de Desenvolvimento Rural e Sustentável (CONDRAF) no que se refere a temática da juventude rural.

Em seguida, realizamos 5 entrevistas em profundidade com gestores públicos que ocuparam cargos na SNJ e no MDA, entre 2011 e 2015, período de realização das duas últimas Conferências. Além dessas entrevistas com gestores, realizamos 5 entrevistas com representantes de organizações do movimento rural ligados à temática da juventude. O quadro 01 apresenta os entrevistados para a pesqui$\mathrm{sa}^{5}$, os cargos ocupados no período das Conferências, as vinculações sociais e as trajetórias políticas.

Quadro 01. Relação dos entrevistados, instituições governamentais ou organizações sociais que representam, cargos ocupados e trajetórias políticas

\begin{tabular}{|c|c|c|}
\hline Entrevistados (as) & $\begin{array}{l}\text { Instituições governamentais } \\
\text { ou organizações sociais/ } \\
\text { cargos ocupados (2008-2015) }\end{array}$ & Trajetórias políticas \\
\hline Severine Macedo & $\begin{array}{l}\text { SNJ / Secretária Nacional de } \\
\text { Juventude (2011-2014) }\end{array}$ & $\begin{array}{l}\text { Movimento sindical rural / } \\
\text { partido político }\end{array}$ \\
\hline Gabriel Medina & $\begin{array}{l}\text { SNJ / Secretário Nacional de } \\
\text { Juventude (2015-2016) }\end{array}$ & $\begin{array}{l}\text { Movimento estudantil / } \\
\text { partido político }\end{array}$ \\
\hline Divaneide Basílio & $\begin{array}{l}\text { SNJ / Chefe de Gabinete } \\
(2011-2012)\end{array}$ & $\begin{array}{l}\text { Pastoral de juventude / } \\
\text { partido político / movimento } \\
\text { de juventude / Secretária } \\
\text { estadual de Juventude no Rio } \\
\text { Grande do Norte (2015-2016) }\end{array}$ \\
\hline Elisa Guaraná & $\begin{array}{l}\text { SNJ / Coordenadora da pasta } \\
\text { de Juventude (2011-2015) }\end{array}$ & Partido político / academia \\
\hline Luiza Dulci & $\begin{array}{l}\text { MDA / Coordenadora da pasta } \\
\text { de juventude (2015-2016) }\end{array}$ & $\begin{array}{l}\text { Movimento estudantil / } \\
\text { partido político }\end{array}$ \\
\hline E. K. & MST / Setor de educação & $\begin{array}{l}\text { Movimento social / partido } \\
\text { político }\end{array}$ \\
\hline
\end{tabular}




\begin{tabular}{|l|l|l|}
\hline A. F. & $\begin{array}{l}\text { Fetraf-RN / Coordenação de } \\
\text { juventude }\end{array}$ & $\begin{array}{l}\text { Movimento de Igreja / } \\
\text { movimento sindical rural }\end{array}$ \\
\hline G. P. & Pastoral da Juventude Rural & Pastoral da Juventude \\
\hline M. B. & $\begin{array}{l}\text { CONTAG / Diretoria de } \\
\text { Juventude }\end{array}$ & Movimento sindical rural \\
\hline A.N. & MST e Via Campesina & Movimento social \\
\hline
\end{tabular}

Fonte: Pesquisa dos autores, 2020. Elaboração própria.

O artigo está estruturado em três partes, além desta introdução. Na primeira parte, exploramos como a juventude rural vai se tornando referência no campo político, seja pela maior organização e sensibilização dos movimentos rurais por essa temática, seja pelo papel central do Estado na institucionalização de políticas públicas para essa categoria. Na segunda parte, fazemos uma breve contextualização histórica do reconhecimento da juventude rural enquanto agente importante no campo político. Esse processo leva a uma maior participação dessa juventude no processo das Conferências, conforme destacamos nas narrativas dos jovens explicitadas na terceira parte do texto. Por fım, apresentamos as considerações finais.

\section{Os Governos Lula e Dilma: a juventude rural entra em cena no campo político}

A juventude rural, enquanto grupo social, deve ser entendida conforme as postulações de Thompson (1987) e Bourdieu (1989), sistematizadas por Picolotto (2014, p.SO71):

a gênese de um grupo social não deve ser entendida apenas pelos processos econômicos ou pelas elaborações teóricas que orientam as ações dos outros atores, mas também devem ser levadas em conta as experiências de organizações políticas e as posições que os atores assumem no campo político.

Influenciado pela ideia de campo de Max Weber, Bourdieu avança na conceituação ao compreender os campos enquanto espaços so- 
ciais orientados por práticas e estruturas hierárquicas. Para o autor, à medida que essas estruturas influenciam na produção de hábitos sociais, também são influenciadas pelos agentes que o compõem. Para Bourdieu (1983, p. 89) "um campo [...] se define entre outras coisas através da definição dos objetos de disputas e dos interesses específicos que são irredutiveis aos objetos de disputas e aos interesses próprios de outros campos".

Desse modo, o campo político exerce papel influenciador nas dinâmicas sociais e nas ações dos indivíduos, mas ao mesmo tempo, é influenciado por aqueles que o pertencem, modificando as relações sociais, costumes e práticas.

"Mas, apesar da agenda nacional sobre juventude ser recente, os moldes para concretização desse processo vem sendo desenhado ao longo de gerações, em função das dinâmicas societárias que a juventude tem imprimido ao longo do tempo" (SANTOS, 2016, p.04), especialmente a juventude organizada em diretorios centrais (DCEs) que teve um papel importante nos governos militares. O fato de a juventude do movimento estudantil ter tido um papel importante no cenário político brasileiro, acabou invisibilizando outras juventudes, conforme destaca o representante da Via Campesina:

a primeira coisa que a gente lutava ou a gente exigia era um certo reconhecimento da juventude rural também como uma categoria (...) quando se falava em juventude naquela época vinha a cabeça os estudantes, quase sempre os estudantes urbanos de classe média. Isso veio muito da trajetória de luta contra a ditadura militar (entrevista concedida aos autores em out. 2020).

No caso da juventude rural, assim como no caso da categoria agricultura familiar identificada por Picolotto (2014), o seu surgimento político é "produto de sua própria experiência de "fazer-se" enquanto atores políticos, com identidade e projeto próprio, em diálogo com as elaborações acadêmicas e em uma relação ora conflituosa, ora de colaboração com setores do Estado" (PICOLOTTO, 2014, p. S071). 
Nota-se que os movimentos rurais começaram a introduzir, especialmente a partir dos anos 90, a discussão sobre a juventude dentro das suas entidades, ao passo que estava sendo revelado pelos dados do IBCE que "entre 1996 e 2000, as áreas rurais perderam mais de 1,6 milhões de jovens que migraram para as cidades" (OLIVEIRA, CELUPPI e KOHWALD, 2011, p. 36). A problemática da sucessão rural passou, então, a ser pautada dentro das organizações conjuntamente com outras demandas por acesso a crédito, educação de qualidade, trabalho e infraestruturas básicas para quem vive no campo.

No site da Contag consta que no início da decada de 1990 os jovens rurais iniciaram o processo de garantir seu espaço na estrutura organizativa do sindicato, e somente no $8^{\circ}$ Congresso Nacional dos Trabalhadores Rurais, em 2001, os delegados e delegadas deliberaram pela criação das Comissões e Coordenações da Comissão de Jovens em todas as três instâncias do movimento sindical - sindicatos, federações e CONTAG.

Em meados dos anos 2000, os sindicatos ligados a Federação Nacional dos Trabalhadores e das Trabalhadoras da Agricultura Familiar do Brasil (FETRAF) buscaram organizar nacionalmente a juventude rural a qual estava associada, "contribuindo fundamentalmente para a definição de uma pauta de reivindicações específicas, na luta pela defesa de interesses e representação política de rapazes e moças rurais" (OLIVEIRA, CELUPPI e KOHWALD, 2011, p. 36), além de terem fortalecido a proposição da criação do Comitê Permanente de Juventude no Condraf.

Assim, conforme destaca Macedo (2019, p.14), o processo de organização dos jovens rurais no seio das organizações e movimentos sociais e sindicais do campo cresce em conjunto com as demandas por políticas públicas e políticas agrícolas, além da necessidade de um lugar de destaque nas singularidades juvenis dentro das próprias organizações.

Nos anos 2000, a juventude rural passou a ganhar maior visibilidade na esfera pública e dentro dos próprios movimentos sociais rurais. Segundo Castro et al. (2009), vários movimentos sociais rea- 
lizaram encontros, congressos e acampamentos, dentre eles: I Congresso Nacional de Juventude Rural (Pastoral da Juventude Rural - PJR e Movimento dos Trabalhadores e Trabalhadoras Sem Terra - MST), Encontros de Juventude do Campo e da Cidade (MST), Acampamentos da Juventude da Agricultura Familiar (Fetraf), Seminário do Programa Jovem Saber (Contag) e VI Acampamento Latino-Americano de Jóvenes (Via Campesina). Esses espaços viabilizaram um maior foco na juventude rural, inclusive fortalecendo a participação juvenil nos espaços de direção desses movimentos.

$\mathrm{Na}$ esteira dos avanços quanto a participação dos jovens rurais, também no início dos anos 2000, durante primeiro governo Lula, houve a institucionalização da juventude enquanto categoria social e política a partir da criação da Secretaria Nacional de Juventude (SNJ) e do Conselho Nacional de Juventude (Conjuve), em 2005, garantindo políticas públicas e direitos básicos para a juventude brasileira. Ressalta-se também a instalação da Frente Parlamentar em Defesa da Juventude na Câmara dos Deputados, em 2005, coordenada por Reginaldo Lopes (PT/MG), que contava com 118 deputados e 08 senadores.

A Câmara dos Deputados criou, em 2003, uma Comissão Especial para a Juventude (CEJUVENT), com o propósito de estudar políticas públicas para a juventude, culminando com a realização de uma série de audiências públicas, seminários e uma conferência nacional. Esta ação da Câmara gerou uma considerável quantidade de iniciativas legislativas sobre juventude, a exemplo do Estatuto e do Plano Nacional da Juventude (SANTOS, 2016, p.11).

A criação, nos anos 2000, de secretarias, fóruns, câmaras e instituições participativas voltadas para a juventude foi resultado do crescimento da participação social dos jovens nas organizações políticas, movimentos sociais, partidos políticos, associações etc. desde a década de 70 (CARNEIRO e CASTRO, 2007). Conforme destaca Severine Macedo, em uma fala de abertura da II Conferência Nacional de Juventude ${ }^{6}$, em 2008, 
A partir do governo Lula, surge uma nova abordagem do tema juventude em âmbito nacional e os jovens se tornam um dos segmentos mais beneficiados pelos avanços das políticas sociais e de desenvolvimento econômico.

Beto Cury, primeiro Secretário Nacional de Juventude, também reafirma a importância desse período para o reconhecimento da juventude como agente importante no campo político. Quando participou do evento da assinatura do Pacto pela Infância e Juventude e do decreto de lançamento da Conferência Estadual da Juventude, em 2007 em Curitiba (PR), ele destacou:

Hoje, posso dizer com muita tranqüilidade que a juventude deixou de ser olhada apenas como transição da adolescência para a vida adulta, passando a ser percebida como segmento social, e o jovem, como sujeito de direitos e agente importante de qualquer projeto de desenvolvimento do país?

A juventude, que até então era tida como um problema social, começa a ser reconhecida como uma categoria importante no processo de desenvolvimento do país. Esse reconhecimento tem a ver também com o que Vázquez e Cozachcow (2017, p. 2) denominaram de um "regresso à política”, ou seja, "um reencantamento com a representação político-partidária e com as instituições formais da política [além de] um maior compromisso da juventude e um massivo ingresso dos jovens na militância”. Assim, os jovens passaram a ser reconhecidos como sujeitos de direitos e que necessitavam de políticas públicas específicas, ou seja, passaram de "agentes que podiam considerar-se, ou ser considerados, como expectadores do campo político e tornaram-se agentes em primeira pessoa" (BOURDIEU, 2011, p. 201).

Nota-se, portanto, a importância dos contextos e das condições sociopolíticas que influenciam a ação política da juventude rural, ou seja, o reconhecimento do "sistema político institucionalizado (Governo e Sistema de Partidos, fundamentalmente) como facilitador e promotor implícito do surgimento de ações coletivas e movimentos sociais" (RUIZ, 2014, p.15). 
Para Vázquez (2015, p. 10) “a produção estatal de 'juventude’ como categoria social pode ser reconhecida, por exemplo - embora não exclusivamente - no âmbito das políticas públicas". Ainda para Vázquez (2013), as especificidades da juventude enquanto categoria são produtoras de capital político que configuram papel determinante na identificação dos jovens enquanto categoria política, a partir de simbolismos. Essa identificação, segundo a autora, pode produzir o estímulo à mobilização coletiva juvenil.

As especificidades da juventude são produzidas simbolicamente como um valor ou capital político, como uma geração, como um princípio de recrutamento de militantes, de reconhecimento ou de identificação, entre outros dos sentidos explorados (VÁZQUEZ, 2013, p. 22).

A discussão iniciada em torno do Estatuto da Juventude, em 2005, também reafirma a entrada da temática da juventude na agenda governamental e mostra o resultado das articulações entre diversas organizações, acadêmicos e gestores que já vinham fazendo pressão no Legislativo. Desse processo, várias parcerias foram construídas e que depois se tornaram base para a elaboração de políticas públicas. Em entrevista com Elisa Guaraná, pesquisadora da temática de juventude no Brasil, ela destaca a importância das mobilizações em torno do Estatuto da Juventude para a conformação de redes que se tornaram importantes na consolidação da juventude rural como ator político. A sua experiência nesse processo fez com que ela articulasse com Severine Macedo e com outros movimentos, fomentando processos de formação política, conforme relatado:

Em 2005 também estava acontecendo o debate do Estatuto da Juventude no Congresso, eu cheguei a participar de espaços onde ela [Severine] também estava e a gente sempre foi mantendo contato muito próximo. A gente fez [uma] pesquisa em um diálogo muito intenso com os movimentos sociais [...] com o MST, a Via Campesina e, com a Contag, eu estabeleci uma rela- 
ção de formação [...] Aquele período foi um período muito rico. Então, entre 2005 e 2008, foi um período de efervescência, me aproximei muito da PJR nesse processo (Elisa Guaraná, entrevista concedida aos autores em set 2020).

A criação de mecanismos institucionais como a Secretaria Nacional de Juventude (SNJ) e o Conselho Nacional de Juventude (Conjuve), em 2005, a realização da I Conferência Nacional de Juventude (CNJ), em 2008 e a aprovação do Estatuto da Juventude, em 2013, significou importante avanço na institucionalização da juventude e reconhecimento social e histórico enquanto categoria. Somados à diversas outras iniciativas em âmbito federal, estadual e municipal, esses mecanismos institucionais possibilitaram a expansão da compreensão do jovem enquanto ator político e social pelo poder público e pela sociedade ao fortalecerem a participação da juventude nesses espaços. Esses avanços institucionais e seus desdobramentos ficaram conhecidos na Política Nacional de Juventude, inserindo de maneira central os jovens no debate e na proposição de políticas públicas.

A partir da Política Nacional de Juventude - conjunto de ações e espaços institucionais voltados para os jovens - houve uma reestruturação de algumas políticas públicas já existentes para o campo, como o PRONAF Jovem e a linha de crédito Nossa Primeira Terra, do Programa Nacional de Crédito Fundiário (PNCF), além do surgimento de outras novas, como o Programa de Fortalecimento da Autonomia Econômica e Social da Juventude Rural (Pajur). Políticas educacionais também tiveram uma forte inserção no meio rural, como o Programa Universidade para Todos (ProUni) e Programa Nacional de Acesso ao Ensino Técnico e Emprego (PRONATEC). Essas políticas públicas, principalmente as mais direcionadas para a juventude rural, enfrentarem limitações na sua implementação. De acordo com Severine, em sua entrevista:

Foram 4 anos de gestão, com duas eleições no meio, ou seja, no primeiro ano você estabelece o PPA [Plano Plurianual], faz o seu planejamento e começa a executar a sua agenda no segundo 
ano [...] é completamente desumano pensar na implementação de agendas estruturantes em 4 anos. No máximo [conseguimos] estabelecer parâmetro, abrir espaço, fazer pactuação e instituir os canais formais que permitam que uma gestão seguinte aprofunde. O grande legado foi fazer essas pontes, articulações com vários ministérios, que abriram canais para a juventude rural, para os movimentos e para estabelecer a agenda.

Entretanto, vale ressaltar que essa movimentação da juventude no campo político também foi repleta de tensões e conflitos, que se expressavam com muita força nas discussões e deliberações do Conjuve, especialmente nos períodos eleitorais. De acordo com Gabriel Medina, as disputas dentro do Conjuve refletiam as diferenças das tendências dentro do Partido dos Trabalhadores. Esses conflitos internos entre representantes da juventude do mesmo partido realçam a diversidade da juventude do país e a disputa por ocupação de cargos nos espaços de poder.

[Foi] no convívio do Conjuve que eu tive muito apoio dos movimentos sociais. Se eu não me engano, quando fui presidente do Conselho tive o apoio da CONTAG. A FETRAF não, pois fechou com a CNB [tendência dentro do PT] numa posição que depois gerou um baita conflito político entre nós, que foi quando a juventude do PT não me apoia para presidente do Conselho e eu viro presidente do Conselho sem o apoio do PT, mas sendo do PT, e o PT apoiando o PSB (Gabriel Medina em entrevista concedida aos autores em out 2020).

Além disso a maior visibilidade da juventude dentro das organizações rurais não se deu de maneira tranquila. As relações conflituosas e hierárquicas vivenciadas por jovens rurais (SILVA JÚNIOR, 2020) são refletidas na negação das capacidades dos jovens por parte dos mais velhos, como destaca o representante do MST e Via Campesina:

A gente foi construindo isso na base de muita discussão, de enfrentar muito preconceito dentro dos nossos movimentos, os sindicatos sofreram muito com isso, foi um debate geracional 
muito forte, impedindo que os jovens pudessem participar de eleição de sindicato, as mulheres sofriam isso muito mais do que nós homens. Era uma luta para fora, para a gente se fazer reconhecer para outras juventude, mas era também uma luta muito grande internamente dentro dos movimentos (representante da Via Campesina, entrevista concedida aos autores em out. 2020).

Portanto, destaca-se que, apesar das inovações institucionais e das mobilizações da juventude nos diversos espaços, em vários momentos houve confrontos explícitos, inerentes à própria estrutura dos campos (BOURDIEU, 1989).

O protagonismo da juventude rural na SNJ se consolidou em 2011, com a nomeação de Severine Macedo como secretária nacional de juventude. Inclusive, a atuação em prol da juventude rural foi reconhecida por Gabriel Medina, conforme relato: “obviamente a gestão da Severine teve uma marca importante nesta pauta [da juventude rural], articulando com alguma força o tema a partir do Comitê de Juventude Rural e das políticas".

Ressalta-se que o processo de escolha do nome de Severine para assumir a SNJ, no primeiro mandato do governo Dilma, não foi tranquilo pela própria diversidade das juventudes que estavam atuando efetivamente no Conjuve. Havia outros nomes que estavam sendo discutidos, mas ao final, muitas organizações da juventude rural apoiaram Severine, conforme relembra Elisa Guaraná:

Em 2010, no final do ano, já começou o amadurecimento do nome dela [Severine] para a Secretaria. Foi um processo complexo, que no final deu certo. Com várias pessoas, e é importante dizer isso: teve uma carta de várias organizações de juventude rural apoiando o nome dela. Isso para a gente entender o peso que representava ser a segunda secretária, a primeira secretária jovem. Foi uma disputa pesada para ela entrar (Elisa Guaraná em entrevista concedida aos autores em set 2020. Grifo nosso). 
Em entrevista, Severine tambem relembra esse aspecto:

Com a eleição da Presidenta Dilma, começou uma movimentação forte das juventudes partidárias, que isso é bem natural, isso aconteceu no governo do presidente Lula,(...) Naquele período, o PMDB apresentou nome, o PCdoB, o PSB, o PDT. O PT tinha dois nomes: o meu e o do Carlão, que era um quadro, era inclusive funcionário da secretaria da juventude da gestão do Beto e o PCdoB indicou Danilo Moreira, que era secretário adjunto do Beto Cury na secretaria de juventude na gestão do presidente Lula e foi presidente e vice-presidente do Conjuve, né? Então esses eram os nomes que estavam colocados ali na roda. Houve uma movimentação muito forte dos partidos por meio de parlamentares, das suas direções, de indicar os nomes dos seus partidos (...) houve também uma movimentação importante dos movimentos de juventude em defesa do meu nome (Severine Macedo, entrevista concedida aos autores, set 2020).

Por sua trajetória nas lutas dos movimentos sociais rurais, Severine reorganiza a SNJ buscando dar centralidade aos jovens do campo. Assim, a juventude rural passou a ter maior visibilidade em nível nacional em relação às pautas defendidas e no processo de afırmação do jovem do campo enquanto categoria política (MOURA, SILVA, SILVA JUNIOR, 2018). Esse processo de construção identitária perpassou ainda, o processo de articulação para a adequação de políticas públicas de juventude já existentes, como o Projovem, para a realidade da juventude rural, por meio da criação de um GT de políticas públicas da juventude rural na SNJ.

[...] antes disso [da II CNJ] a gente tinha montado o GT, ele não estava lá ainda, estava indo e voltando. A gente fez um GT de políticas para a juventude rural e todas as organizações decidiram entrar, foi uma das primeiras decisões da Severine. Tinha que ter uma pauta e recuperar muito da agenda que estava sendo construída, não tinha uma agenda nova naquele momento, era muito do que já estava construído (Elisa Guaraná, entrevista concedida aos autores, set 2020). 
Ainda em 2011, foi criado o Comitê Permanente de Promoção de Políticas para a Juventude Rural (CPJR) do CONDRAF, do Ministério do Desenvolvimento Agrário. O Comitê foi criado diante do entendimento do Conselho de que havia uma invisibilidade da juventude rural e que as políticas existentes não davam conta de satisfazer as demandas dessa categoria. De acordo com o documento de criação do Comitê:

Ao longo da história as políticas públicas desconsideraram a participação da juventude do meio rural e não desenvolveram estratégias para estimular a inclusão de jovens nas políticas de desenvolvimento rural sustentável. [Considera-se, também] a situação de invisibilidade da juventude rural e a constatação de que as políticas que existem não conseguem atender as demandas de jovens (CONDRAF, 2011, p. 02).

As principais atribuições do Comitê giravam em torno da proposição, análise e estudos sobre as políticas públicas para a juventude rural, promover e estimular o debate sobre a juventude rural articulado com as ações e temas a serem discutidos no âmbito do Conselho Nacional de Juventude e pautar o Plenário do CONDRAF de temas relacionados a Juventude Rural.

Segundo a ex-Assessora Especial de Juventude do MDA (Ana Carolina Silva) a "consolidação do Comitê vai possibilitar uma atuação conjunta, tanto para dentro do Ministério quanto de forma interministerial trabalhando para agregar o conjunto de políticas públicas para juventude rural" (DF Rural, 2015).

Em 2012, com a realização do I Seminário Nacional de Juventude Rural e Políticas Públicas (SNPPJR), a juventude ganha notoriedade dentro do governo. Fruto da articulação entre a SNJ e o MDA, o Seminário contou com a presença de três gestores do alto escalão: Pepe Vargas, então Ministro do Desenvolvimento Agrário, Gilberto CarvaIho, da Secretaria Nacional da Presidência da República, e Severine Macedo, Secretária de Juventude a época, além da presença massiva de representações das principais organizações da juventude rural do país: MST, Fetraf, Contag, PJR, entre outras ${ }^{8}$. 
Dentre as principais questões discutidas pela juventude rural, destaca-se a problemática do êxodo rural e as dificuldades enfrentadas pelos jovens para acessar direitos.

Segundo o relatório final do Seminário (SNJ, 2012, p.27), “ocorreu consenso em relação à necessidade de uma Política que efetivamente garanta as condições de vida, trabalho e renda, e acesso a direitos como educação, saúde e mobilidade". O Seminário também foi um espaço de mostrar a força da juventude rural no campo político brasileiro. Desse Seminário foi elaborado um documentário intitulado Pé de Formigueiro, com várias narrativas de jovens sobre a sua participação nesse evento e a importância dessa categoria no processo político do país. Segundo a fala de um jovem "A nossa juventude rural e muito qualificada, ela tem propostas para serem efetivadas. O que a gente precisa é conseguir operacionalizar".

A força da juventude rural para transformar determinadas realidades também vai ser destacada por outro representante da juventude rural, que ainda complementa se questionando sobre as possibilidades dessa transformação tanto em âmbito institucional quanto também por meio de outras frentes. Segundo esse jovem:

a juventude tem um papel fundamental para alterar essa realidade. Acho que o debate é se a gente consegue alterar dentro somente da luta institucional ou se é necessárias outras propostasnecessárias outras propostas [...] e quais os limites das políticas públicas que a gente já vem apontando e observando. E o que é possível fazer para alem dessas políticas públicas também.

As demandas dessa juventude incluem também questões de acesso à cultura e não somente políticas ligadas a dimensão agrícola, conforme destaca uma outra representante da juventude rural no Seminário:

além das políticas públicas que a gente está discutindo aqui no Seminário, a gente precisa de incentivo cultural, né? Que não e só esses projetos de bancar o Pronaf, bancar projetos financeiros e econômicos. A gente precisa de incentivos que vai dizer para essa juventude que não precisa estar só no meio rural, 
mas que ela precisa conhecer outros meios e que não precisa sair do campo para fazer isso.

A realização, por parte dos movimentos, de encontros e seminários para a juventude rural somado à criação de espaços institucionais e a entrada de jovens rurais na burocracia estatal nos governos Lula - e a continuidade da agenda no governo Dilma -, resultaram num processo de ampliação e consolidação da juventude rural no campo político. Essa consolidação foi potencializada, entre outros aspectos, pela realização das Conferências Nacionais, abordadas na seção seguinte.

\section{A participação da juventude rural nas Conferências e as narrativas construídas}

As Conferências Nacionais de Políticas Públicas de Juventude enquanto instituições participativas representaram, para o conjunto da juventude brasileira, um espaço de participação social e politização, além de um espaço impulsionador da organização política dos diversos grupos que construíram esses espaços. Conforme destacam Rocha e Romão (2016, p. 201):

a criação da [Política Nacional de Juventude] PNJ e de suas estruturas de gestão [...] gerou um novo foco de mobilização para determinados segmentos de jovens, especialmente aqueles articulados em partidos políticos, movimentos sociais, entidades da sociedade civil, sindicatos, movimento estudantil, igrejas e tantas outras formas de organização.

Para a juventude rural, o processo das Conferências impulsionou maior organicidade entre os jovens e um alinhamento das pautas já defendidas nos diversos movimentos rurais. Nesse sentido, os jovens do campo viram nas Conferências mais uma possibilidade de discutir e pautar antigas demandas, como: reforma agrária, emprego e renda no campo, esporte e lazer, agroecologia, mercados justos etc.

Já na primeira Conferência, em 2008, acontece uma organização da juventude rural frente à disputa política inerente às Conferências. No 
processo de construção, a Secretaria propõe uma Conferência específica para a juventude rural: a Conferência Nacional de Juventude de Povos e Comunidades Tradicionais. Entretanto, a juventude rural se unifica e não aceita essa proposta, preferindo construir e participar da Conferência Nacional de Juventude regular. Elisa Guaraná que acompanhou a I CNJ como pesquisadora, afırma que o primeiro dia do evento foi marcado por um "levante da juventude rural" ao perceber que não existia nenhum Grupo de Trabalho voltado para a juventude do campo, a categoria se mobilizou e pautou um GT de juventude rural durante a Conferência, além de aprovar uma moção sobre reforma agrária ao final da plenária:

A conferência de 2008 é marcada, na sua abertura, por um levante da juventude rural, que se junta no fundo do plenário e exige um GT, um GT formado com todas as organizações rurais que estavam ali presentes e participam da articulação. A juventude rural faz uma moção em defesa da reforma agrária, é uma moção amplamente votada e diria que é a principal presença da conferência é a moção sobre reforma agrária (Elisa Guaraná, entrevista concedida aos autores, set 2020).

Beto Cury, em um relato presente na Resolução da $1^{a}$ Conferência (SNJ, 2008, p. 10), mostra como esse momento foi importante para mostrar a diversidade das juventudes do país. Segundo ele, "foi uma Conferência que conseguiu mobilizar um conjunto de atores de diversos segmentos juvenis, o que possibilitou um processo profundo e amplo de debates sobre a construção de uma Política Nacional de Juventude".

Neste sentido, já na primeira Conferência, a juventude rural revela certa organicidade ao conseguir de forma unificada pautar um GT durante o evento, além de conquistar quantidade expressiva de votos na moção sobre reforma agrária, que se configura como a principal demanda dos movimentos do campo. Os diversos movimentos de juventude vão se organizando, inclusive, no sentido de criar uma narrativa que sensibilizasse outros coletivos de juventude para agregar a causa da juventude rural, conforme o relato abaixo: 
Hoje não, mas antes a gente chegava nas Conferências sem nem conhecer as pessoas e você precisa conversar com elas para que elas possam votar em você e a gente vai mostrando as propostas, dizendo que quer representar os jovens agricultores. E acho que foi muito positivo todo esse momento (representante da Fetraf RN em entrevista concedida aos autores, set 2020).

Destaca-se ainda os desafios dessa empreitada, pois são vários interesses sendo disputados nos espaços das Conferências, mas as trocas vão sendo feitas na tentativa de abarcar o maior número de demandas possíveis. O entrevistado da Fetraf conta um pouco sobre isso:

Não é fácil, tanto para os movimentos citados [estudantil, negro, indígena, entre outros], como pra gente. Mas, assim, eu acho que foi uma troca mútua. Tanto eles precisavam que a gente fosse sensivel às pautas deles, quanto nós também precisávamos (representante da Fetraf RN em entrevista concedida aos autores, set 2020).

Em 2011, ocorre a segunda edição da Conferência Nacional de Juventude que teve como prioridade a aprovação do Estatuto da Juventude, que até então estava em tramitação na Câmara dos Deputados. Além disso, foi o momento de discutir a emergente necessidade de elaboração de um plano de enfrentamento aos homicídios de jovens negros e pobres, o que veio a desembocar no Plano Juventude Viva, ação interministerial de enfrentamento aos homicídios da juventude negra. Sobre a juventude rural, a $2^{a}$ Conferência priorizou:

a criação de uma política pública de fomento específica para a juventude da agricultura familiar, camponesa, assalariada rural, para os povos e comunidades tradicionais [...], que respeite os seguintes princípios: (a) priorização, associativismo e cooperativismo; (b) valorização de práticas agroecológicas alternativas; (c) acesso à terra e reforma agrária; (d) priorização da participação dos jovens dos movimentos sociais e do campo na elaboração e no monitoramento dessa política; (e) desburocratização das políticas já existentes e das novas políticas; (f) qualifıcação técni- 
ca na produção, na gestão e na comercialização; (g) geração de renda respeitando a pluriatividade (BRASIL, 2011, p. 3).

Como podemos observar na prioridade destacada acima relativa ao Eixo 2: Direito ao Território, surge a valorização da participação da juventude rural como reivindicação, sem deixar de apontar a Reforma Agrária, o acesso à terra e às políticas públicas como bandeiras.

Conforme destaca Divaneide Basílio, em entrevista concedida aos autores, o lugar da juventude rural foi se ampliando desde a primeira Conferência, em 2008, especialmente porque houve uma maior organização em âmbito nacional dessa juventude: "Os grandes movimentos e as federações (Fetraf e Contag) e a própria Via Campesina apresentaram pautas específicas da juventude, seja no Abril Vermelho, nas Jornadas de Luta, na Marcha das Margaridas" (Divaneide Basílio, ex-chefehefe de Gabinete da SNJ, entrevista concedida aos autores, 2020). Decorreu-se disso, uma maior articulação e organização da juventude rural na Conferência Nacional de Juventude de 2011. Divaneide ainda ressalta: “A Conferência de 2011 teve um sabor diferenciado para a juventude rural. Tinha um sentimento de organização a mais. Tinha uma sintonia, um diálogo mais estreito entre todos os espaços que articulavam a juventude rural". Combinado a isso, o fato de ter uma representante do movimento de juventude rural ocupando o cargo como Secretária Nacional de Juventude também contribuiu para dar visibilidade a esse grupo. Segundo Divaneide, "ter uma Secretária Nacional que veio da base da Fetraf tem um diferencial".

Impulsionados pelo Programa Territórios da Cidadania ${ }^{9}$, os comitês e câmaras temáticas de juventude tiveram papel importante na organização, divulgação e participação nas etapas territoriais e posteriormente na estadual, levando a juventude rural a ocupar esses espaços de maneira substantiva. A série de ações oriundas do processo de institucionalização da juventude enquanto categoria política atreladas ao surgimento de mecanismos institucionais voltados para a juventude rural também possibilitaram uma abertura no diálogo da juventude ru- 
ral com outros segmentos nas Conferências. Com isso, os jovens rurais obtiveram êxito na eleição de propostas do meio rural, mas também na eleição de delegados para a etapa estadual e nacional.

Nota-se que como uma das primeiras ações de promoção da visibilidade da juventude rural, foi a realização no ano de 2012 do I Seminário Nacional de Juventude Rural (SNJR), promovido pela SNJ em parceria com o MDA. Segundo o seu Relatório Final (2012, p. 5), para a SNJ, esse momento "representou um encontro com a juventude rural, que desde a primeira hora se colocou de forma colaborativa na construção dessa nova gestão da SNJ", pois a ideia desse espaço já era debatida no CONDRAF, no Grupo de Trabalho da Juventude Rural. Assim, o "I Seminário Juventude Rural e Políticas Públicas ocorre como parte da trajetória do diálogo entre o governo e os movimentos sociais na busca de uma Política Nacional que atenda os anseios e as necessidades dos e das jovens rurais" (p. 6).

Dentre as principais proposições de políticas públicas sistematizadas por eixo ${ }^{10}$ a partir desse Seminário destacam-se: acelerar a política de reconhecimento e titulação das terras dos povos e comunidades tradicionais.

Portanto, destaca-se que foi um processo crescente de articulação e mobilização da juventude rural no campo político brasileiro, que se inicia no início dos anos 2000, mas que vai se consolidando ao longo dos anos, ou seja, "ao longo das Conferências fomos dando visibilidade a juventude rural".

A $3^{a}$ Conferência Nacional de Políticas Públicas de Juventude ocorreu em 2015, sob o tema "As várias formas de mudar o Brasil", e promoveu novas maneiras de participação da juventude, incluindo a interação on-line através de um aplicativo exclusivo. Como destacam Moura, Silva e Silva Jr (2018) a terceira Conferência, além de defınir prioridades entre as resoluções de cada eixo temático - trabalho, saúde, segurança, educação, território e mobilidade, participação, diversidade, meio ambiente, comunicação, cultura e esporte - também de- 
finiu três prioridades gerais da Conferência, por meio dos delegados eleitos durantes as etapas anteriores à nacional, das quais uma delas teve participação direta da juventude rural:

Ampliar e acelerar o processo de Reforma Agrária e regularização fundiária, bem como reconhecimento e demarcação de terras pertencentes a povos e comunidades tradicionais, em especial das terras indígenas e quilombolas, acabando com as práticas forçadas de remoção de seus territórios. Assim, viabilizando a regularização da documentação de assentamentos já existentes, permitindo que os jovens tenham condições de permanecer ou regressar às suas terras originais, e serem assim contemplados pelos programas, projetos e ações para a juventude rural (BRASIL, 2016, p. 8).

Percebemos, aqui, a continuidade da preocupação da juventude com a sucessão rural, com o enfrentamento do esvaziamento do campo, com a promoção de direitos e vida digna nesse ambiente.

A $3^{a}$ Conferência também foi produto de muitas articulações nos Territórios da Cidadania. Houve uma grande investida do Governo Federal em possibilitar a realização de Conferências Territoriais, a partir dos GTs de juventude dos Colegiados Territoriais. Isso possibilitou uma grande participação da juventude rural na Conferência Nacional, uma vez que a presença da agricultura familiar nas reuniões dos Colegiados sempre foi central. Luiza Dulci, ex-diretora da pasta de juventude do MDA, destaca esse processo:

Olha, eu estava como conselheira do Conjuve pelo governo (MDA), representando a juventude rural e participei bastante ativamente do processo de organização da Conferência. Não sei como foram as outras, mas naquele período, de a gente não ter recurso, não saber como ia ser, se realmente ia acontecer a conferência, (...), a gente acabou colocando muita força na organização das Conferências Territoriais. Não sei se vocês chegaram a ver, mas foram realizadas mais de 130 Conferências Territoriais (Luiza Dulci em entrevista concedida aos autores, out 2020). 
Percebemos que essa mobilização nos Territórios incentivou a grande representação da juventude rural na Conferência Nacional e, portanto, a possibilidade de pautar uma série de demandas. A organicidade da juventude rural na $3^{a}$ Conferência partiu também da unificação por partes dos movimentos em relação às pautas defendidas pelos movimentos rurais e que perduram até os dias atuais.

Nós trabalhamos dentro de um campo unitário, cada um [movimento] tem sua especificidade, mas temos pautas que são comuns e que a gente precisa juntar força. Claro que existem as divergências, mas principalmente nesse momento que estamos passando [pandemia Covid-19] a gente tem construído um campo unitário da juventude para nos fortalecermos nesse processo (representante da Contag, entrevista concedida aos autores, set 2020).

Destacamos, por fım, a importância dessas Conferências, inclusive para o MST, que tradicionalmente optava pela ausência nos espaços institucionais como os conselhos e as conferências, começou a perceber a importância desses espaços para a proposição de políticas públicas. Segundo o representante do MST, jovem liderança durante a realização das Conferências:

a gente teve participação do nosso coletivo nacional na Conferência [de 2008] (...) [mas só agora] entendemos a disputa institucional nesse processo de luta. Mas lá atrás, por não conhecer, achávamos que era só mais uma coisa que vai e vem, de burocracia institucional, mas a gente entende que [a conferência] é extremamente importante para construção de políticas públicas, que isso vai incidir diretamente no nosso público (representante do MST em entrevista concedida aos autores, set 2020).

Para o representante da Via Campesina, as Conferências produziram um acúmulo significativo na juventude rural e nos movimentos, mas ao mesmo tempo, possuíam entraves que os impediam de exercer uma participação mais efetiva. Para ele, além de o governo ter sido um limitador da participação: "nós só podíamos participar até tal ponto, só podíamos ir até ali", as Conferências eram, para ele, espaços muito mais consultivos do que deliberativos, por isso eles tiveram 
"muita dificuldade em transformar essas boas intenções em políticas públicas, apenas algumas poucas foram implementadas".

Do balanço final das três Conferências, muitos militantes da juventude rural enfatizam a importância desses espaços e reconhecem que nos governos petistas muitas pautas avançaram, mas que com o impeachment de DIlma e a ascensão de Michel Temer, em 2016, e com a eleição de Jair Bolsonaro, em 2018, as políticas públicas para a juventude foram perdendo espaço:

[...] a gente lutava, não conseguia tudo que a gente queria, mas [conseguimos] o mínimo: a aprovação de algumas pautas do rural, o PRONAF Jovem, que foi uma luta desde a PJR, o Plano Nacional de Juventude e Sucessão Rural. A gente estava avançando muito naquele período, infelizmente depois que Dilma saiu foi só caindo (representante da Pastoral da Juventude Rural, entrevista concedida aos autores, set 2020).

Estamos com muita dificuldade a nível nacional por não ter mais esses espaços [conferências, conselhos etc.], mas nos estados a gente tem conseguido que nossa juventude esteja participando desses espaços e também nos municípios: associações, cooperativas da agricultura familiar, conselhos municipais de saúde, de desenvolvimento rural etc. A nível nacional, no governo, não temos espaço para dialogar, mas temos vários deputados orgânicos, que vieram do movimento sindical e que a gente consegue fazer um bom diálogo, temos alguns senadores também. Temos trabalhado também a participação da juventude nos partidos, nesse ano já temos alguns jovens pré-candidatos em seus municípios (representante da Contag, entrevista concedida aos autores, set 2020).

As entrevistas nos revelam um sentimento de ruptura no processo de avanços democráticos e participativos. Os representantes entrevistados reconhecem a importância das Conferências no processo aglutinador de ação coletiva da juventude do campo ao mesmo tempo que reconhecem os efeitos negativos da descontinuidade dos espaços conquistados e das políticas públicas. 


\section{Considerações finais}

As Conferências Nacionais de Juventude, mesmo sofrendo com disputas e relações tensionadas por questões hierárquicas fortemente presentes na vida dos jovens, possibilitaram uma ampliação da capacidade organizativa da juventude rural, enquanto categoria, no Brasil, e foram espaços fundamentais no curso de consolidação da juventude rural no campo político.

Ao mesmo tempo, esse processo impôs, para os jovens, a necessidade de se articularem interna e externamente, seja pautando suas demandas nas Conferências e demais espaços formais da política, como também, pautando a visibilidade dentro dos seus próprios movimentos e organizações. Com isso, as Conferências Nacionais possibilitaram um maior reconhecimento do jovem rural como ator político tanto dentro dos movimentos do campo como também para os demais segmentos das juventudes brasileiras.

Apesar da característica consultiva, os jovens rurais viram nas Conferências uma oportunidade de expressarem suas vozes e suas demandas e construírem redes de cooperação entre as organizações. Mesmo com as divergências entre os movimentos do campo, as pautas gerais e estruturantes foram unificadas nos discursos e nas mobilizações nas três edições (2008, 2011 e 2015). Essa articulação possibilitou que nas três edições, e principalmente na de 2008 e 2015, a pauta da juventude rural estivesse em destaque.

A invisibilidade sentida pela juventude rural no Brasil até o início dos anos 2000, passou a dar lugar para a inserção do jovem do campo nos espaços institucionais da política em nível federal. Para além da unificação das narrativas e das pautas, as Conferências Nacionais - em conjunto com o Conselho Nacional de Juventude - conseguiram incidir, mesmo que minimamente, na participação dos jovens rurais nas políticas públicas, principalmente através da SNJ e do MDA, mostrando a força desse segmento. 
Assim, consideramos que, mesmo no contexto atual adverso às pautas da juventude em nível federal, o fato de a juventude ter se organizado para essas Conferências possibilitou que esses jovens que vivem no meio rural continuem resistindo e propondo pautas nos contextos locais.

\section{Referências}

BOURDIEU, Pierre. O campo político. Revista Brasileira de Ciência Política, no 5. Brasília, janeiro-julho, pp. 193-216. 2011. Disponível em: https://www. scielo.br/pdf/rbcpol/n5/a08n5.pdf. Acesso em: 20 jun. 2020.

BOURDIEU, Pierre. O poder simbólico. Difel: Lisboa; Rio de Janeiro: Bertrand Brasil, 1989.

BOURDIEU, Pierre. Questões de Sociologia. Rio de Janeiro: Editora Marco Zero Limitada, 1983.

BRASIL. Resolução Final da $3^{a}$ Conferência Nacional de Juventude. Brasília: Presidência da República, 2016.

CARNEIRO, Maria José; CASTRO, Elisa Guaraná. Juventude rural em perspectiva. Rio de Janeiro: Mauad X, 2007.

CASTRO, Elisa Guaraná de Castro et al. Os jovens estão indo embora? Juventude rural e a construção de um ator político. Rio de Janeiro: MAUAD X; Seropédica, RJ: EDUR, 2009.

CONDRAF. Resolução no 79 de 19/05/2011 / CONDRAF - Conselho Nacional de Desenvolvimento Rural Sustentável (D.O.U. 08/07/2011). Disponivel em: https://www.diariodasleis.com.br/legislacao/federal/217678-comite-permanente-de-promocao-de-politicas-para-a-juventude-ruralcria-o-comite-permanente-de-promocao-de-politicas-para-a-juventude-rural-do-conselho-de-desenvolvimento-rural-s.html. Acesso em 09 out 2020.

DF Rural. Desenvolvimento Rural Sustentável: Condraf instala mais quatro comitês permanentes. 28 jul 2011. Disponivel em: https://dfrural.wordpress. com/2011/07/28/desenvolvimento-rural-sustentavel-condraf-instala-mais-quatro-comites-permanentes/. Acesso em 09 out 2020.

FARRUGIA, David. Towards a spatialised youth sociology: the rural and the urban in times of change. Journal of Youth Studies, vol. 17, n.03, pp 293-307. 2014. Disponível em: https://www.tandfonline.com/doi/abs/10.1080/136762 61.2013.830700. Acesso em: 15 jul 2020. 
JACINTO, Janério M.; MENDES, César M.; PEREHOUSKEI, Nestor A. O rural e o urbano: contribuições para a compreensão da relação do espaço rural e do espaço urbano. Revista Percurso, Maringá, v.4, n.2, p. 173-191. 2012. Disponivel em: http://periodicos.uem.br/ojs/index.php/Percurso/article/ view/49549. Acesso em: 13 abr 2020.

MACÊDO, Severine C. Educação do campo e jovens rurais. Um estudo sobre demandas educacionais nas conferências nacionais de políticas públicas de juventude. Dissertação (Mestrado) - Programa de Pós-graduação em Educação, Universidade Federal do Estado do Rio de Janeiro, Rio de Janeiro, 2019.

MENEZES, Marilda Aparecida de; STROPASOLAS, Valmir Luiz; BARCELLOS, Sérgio Botton. (Org.). Juventude rural e políticas públicas no Brasil. Brasilia: Presidência da República, 2014. 268p.

MOURA, Joana T. V. de; PONTES, Barbara M. L. A gênese da política de desenvolvimento territorial no Brasil: atores, redes e a comunidade de política pública. Estudos Sociedade e Agricultura, v.28, n.01, pp. 180-207, 2020.

MOURA, Joana Tereza Vaz de; SILVA, Jenair Alves; SILVA JúNIOR, Marcos Aurélio Freire da. Juventude Rural e representação política nas Conferências de Juventude: da construção dos interesses ao diálogo sistematizado. In: COSTA, J. B. A. da; SILVA, M. A. R. da. (Orgs.). Juventudes, cultura e política. Natal: Caravela Selo Cultural, 2018, p. 112-128.

OLIVEIRA, Eliane; CELUPPI, Daniela; KOHWALD, Diego S. A juventude na agenda da Fetraf. Agriculturas, v.08, n.01, pp.36-37, 2011. Disponivel em: http://aspta.org.br/files/2019/10/artigo-7-1.pdf. Acesso em: 27 out 2020.

PICOLOTTO, Everton L. Os Atores da Construção da Categoria Agricultura Familiar no Brasil. Revista Brasileira de Economia e Sociologia Rural, RESR, Piracicaba-SP, Vol.52, Supl. 1, p. S063-S084, 2014. Disponível em: https:// www.scielo.br/pdf/resr/v52s1/a04v52s1.pdf. Acesso em: 11 abr 2020.

POLLETA, Francesca. It was like a fever: storytelling in protest and politics. Chicago: University of Chicago Press, 2006.

ROCHA, Heber Silveira; ROMÃO, Wagner de Melo. Conferências nacionais de juventude: ação coletiva e diversidade como educação política. Cadernos ADENAUER XVII, São Paulo, n. 1, p. 195-215, 2016.

RUIZ, Oscar A. Generaciones: movimientos juveniles, políticas de la identidad y disputas por la visibilidad en el Chile neoliberal. Buenos Aires: CLACSO, 2014. 
SANTOS, Lua G. dos. Juventude, participação e proposição: a agenda da juventude e o Congresso Nacional. In Anais... 10 Encontro da Associação Brasileira de Ciência Política, Belo Horizonte: ABCP, 2016.

SILVA JÚNIOR, Marcos Aurélio Freire da. As estruturas simbólicas e as relações de poder que perpassam a juventude em comunidades rurais: um estudo de caso em Bebida Velha - Pureza/RN. 2020. 101f. Dissertação (Mestrado em Estudos Urbanos e Regionais) - Universidade Federal do Rio Grande do Norte, Natal, 2020.

SNJ. Relatório Final do 1 Seminario Nacional Juventude Rural e Políticas Públicas. Brasilia, DF, 2012. Disponivel em: https://bibliotecadigital.mdh.gov.br/jspui/bitstream/192/144/1/SNJ_relat_fin_juv_rur_2012.pdf. Acesso em 27 out 2020.

SNJ. Caderno de Resoluções da 1 Conferência Nacional de Juventude- Levante sua Bandeira. Brasília, DF, 2008. Disponivel em: http://www.jsb.org. br/anexos/3.pdf. Acesso em 28 out 2020.

THOMPSON, E. P. A formação da classe operária inglesa. Rio de Janeiro: Paz e Terra, 1987.

VÁZQUEZ, M. En torno a la construcción de la juventud como causa pública durante el kirchnerismo: principios de adhesión, participación y reconocimiento. Revista Argentina de Estudios sobre Juventud, v.1, n.7, p. 1-25, 2013. Disponível em: https://perio.unlp.edu.ar/ojs/index.php/revistadejuventud/ article/view/2089/1805. Acesso em: 05 jun 2020.

VÁZQUEZ, Melina. Juventude, política pública e participação: um estudo sobre as produções sócio-estatais da juventude na Argentina recente. Cidade Autônoma de Buenos Aires: Grupo Editorial Universitário, 2015. 88p.

VÁZQUEZ, Melina; COZACHCOW, Alejandro. Activismo juvenil en partidos con gestiones de gobierno a nivel subnacional en Argentina (2007-2015). Revista Sociologia e Política, Curitiba, v. 25, n. 64, p. 47-72, dez. 2017.

\section{Notas}

1 Doutora em Ciência Política (UFRCS). Professora do Programa de Pós-graduação em Estudos Urbanos e Regionais - Universidade Federal do Rio Grande do Norte - Brasil. Orcid: 0001-9561-1063. E-mail: joanatereza@gmail.com.

2 Mestre em Estudos Urbanos e Regionais - Universidade Federal do Rio Grande do Norte - Brasil. Orcid: 0002-5553-6625. Email: marcosaureliojunior@gmail.com 
3 Doutoranda em Psicologia - Universidade Federal do Rio Grande do Norte - Brasil.Orcid: 0000-0001-5222-3837. E-mail: jenairsilva@gmail.com.

4 O relatório citado faz parte do livro "Juventude Rural e Políticas Públicas no Brasil", coordenado e publicado pela SNJ e organizado por Menezes et al. (2014).

5 Os entrevistados que ocuparam cargos como Secretários Nacionais de Juventude e/ou coordenadores da pasta de juventude rural estão identificados pelos nomes verdadeiros pela facilidade de ter acesso a eles pelo ano de ocupação dos cargos. Os demais entrevistados são identificados no texto por letras, evitando a exposição.

6 Discurso da secretária nacional de Juventude, Severine Macedo, na abertura da $2^{\mathrm{a}}$ Conferência Nacional de Juventude. Disponível em: https://www.gov.br/secretariadegoverno/pt-br/assuntos/noticias/noticias-em-acervo/2011/12/10-12-2011-discurso-da-secretaria-nacional-de-juventude-severine-macedo-na-abertura-da-2a-conferencia-nacional-de-juventude. Acesso em: 07 jul 2020.

7 Notícia disponibilizada em http://sta.sites.uff.br/wp-content/uploads/sites/296/2018/01/conferenciadajuventude-19092007.htm. Acesso em 28 out 2020.

8 "Participaram desse evento mais de 40 organizações/movimentos sociais, representantes dos governos federal e estaduais, pesquisadores e professores de programas de licenciatura do campo e de licenciatura indígena, e mais de 140 jovens da agricultura familiar, camponeses, quilombolas, indígenas de todas as regiões do Brasil" (SNJ, 2012, p. 08).

9 O Programa foi criado, em 2008, com o objetivo de promover desenvolvimento econômico e universalizar programas básicos de cidadania por meio de uma estratégia de desenvolvimento territorial sustentável (MOURA e PONTES, 2020).

10 O Seminario foi composto por 02 mesas redondas e 10 oficinas tematicas (sete temas específicos da juventude rural e três oficinas especiais). As oficinas foram assim distribuidas: Oficina 1: Juventude das Comunidades e Povos Tradicionais: igualdade étnico-racial; Oficina 2: Juventude Rural, gênero, sexualidade e diversidade sexual; Oficina 3: Juventude Rural e Trabalho Assalariado; Oficina 4: Juventude Rural da agricultura Familiar e camponesa: trabalho e renda; Oficina 5: Juventude Rural e a sucessão no campo e na floresta: acesso à terra, agroecologia e condições de produção; Oficina 6: Juventude Rural e educação do campo; Oficina 7: Juventude Rural e a permanência no campo e na floresta, cultura, esporte, lazer, saúde mobilidade, tecnologias da informação e comunicação; Ofıcina especial 1: Juventudes Indígenas: igualdade étnica e direito a vida; Oficina especial 2: Juventude Rural e a Rio + 20; Oficina especial 3: Xingú (SNJ, 2012). 


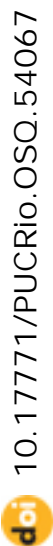

